\title{
Diferimento de pastos de braquiária cultivares Basilisk e Marandu, na região do Cerrado
}

\author{
Valéria Pacheco Batista Euclides ${ }^{(1)}$, Renata Flores ${ }^{(2)}$, Rodrigo Narciso Medeiros ${ }^{(2)}$ \\ e Marcelo Paschoal de Oliveira(1)
}

\begin{abstract}
(1)Embrapa Gado de Corte, BR 262 Km 04, Caixa Postal 154, CEP 79002-970 Campo Grande, MS. E-mail: val@cnpgc.embrapa.br, renata@cnpgc.embrapa.br, marcelo@cnpgc, embrapa.br (2)Universidade Federal do Mato Grosso do Sul, Caixa Postal 549, CEP 79070-900 Campo Grande, MS. E-mail: rodrigo.narciso@ig.com.br
\end{abstract}

\begin{abstract}
Resumo - O objetivo deste trabalho foi avaliar o acúmulo de forragem e o valor nutritivo de pastos de Brachiaria decumbens e Brachiaria brizantha, diferidos em fevereiro e março e pastejados durante o período seco. $\mathrm{O}$ delineamento experimental foi o de blocos ao acaso com parcelas subdivididas. As parcelas principais foram constituídas pelas espécies de Brachiaria e as subparcelas pela época de diferimento. Os pastos diferidos em fevereiro apresentaram maiores massas de matéria seca total (MST) e de matéria seca de lâmina foliar (MSLF) quando comparados aos pastos diferidos em março. As médias para essas variáveis, em fevereiro e em março, foram 4.530 e $3.160 \mathrm{~kg} \mathrm{ha}^{-1}$ de MST, e 935 e $680 \mathrm{~kg} \mathrm{ha}^{-1}$ de MSLF, respectivamente. Independentemente da espécie forrageira e da época de diferimento, houve decréscimos nas massas de forragem disponíveis, nos teores de proteína bruta e na digestibilidade in vitro da matéria orgânica, ao longo do período de utilização. O acúmulo de forragem, em ambas as espécies, foi suficiente para suportar $3 \mathrm{UA} \mathrm{ha}^{-1}$, durante todo o período seco. Independentemente da época de diferimento, os conteúdos de proteína bruta e de energia desses pastos foram limitantes à produção animal.
\end{abstract}

Termos para indexação: Brachiaria decumbens, Brachiaria brizantha, componentes morfológicos, manejo de pastagem, massa de forragem, valor nutritivo.

\section{Deferred pastures of brachiaria cultivars Basilisk and Marandu, in the Cerrados region}

\begin{abstract}
The objective of this work was to estimate the dry matter production and the nutritive value of Brachiaria decumbens and Brachiaria brizantha pastures, deferred in February and March, and grazed during the dry season. The experimental design was a complete randomized block with treatments arranged in a split-plot. The Brachiaria species constituted the main plots, and the deferred months the subplots. The pastures deferred in February showed greater total dry matter (TDM) and blade leaves dry matter (BLDM) yields, when compared to those deferred in March, being in average, 4,530 e 3,160 kg ha-1 of TDM and 935 and $680 \mathrm{~kg} \mathrm{ha}^{-1}$ of BLDM, respectively. Independently of the grass species and deferred months, decreases were observerd in the forage availability, in the percentages of crude protein (CP) and in the in vitro organic matter digestibility (IVOMD) throughout the dry season. The TDM yields were sufficient to sustain $3 \mathrm{AU}^{\text {ha }}{ }^{-1}$, for the whole dry season. Independently of the deferred months, the CP and IVOMD contents of these pastures were limiting factors to animal production.
\end{abstract}

Index terms: Brachiaria decumbens, Brachiaria brizantha, forage yield, morphological components, nutritive value, pasture management.

\section{Introdução}

A produção de forragem não é uniforme ao longo do ano, conseqüência da variação que ocorre na disponibilidade de fatores ambientais para o crescimento, como água, luz e temperatura. No Brasil Central pecuário, a produção de forragem é dividida em período das águas e período da seca. Segundo Pizarro et al. (1996), as gramíneas do gênero Brachiaria acumulam de 77 a
$90 \%$ da produção total de matéria seca durante o período das águas. Conseqüientemente, pastos com essas forrageiras comportam elevadas taxas de lotação nesse período, que são drasticamente reduzidas durante o período seco (Euclides, 2001).

Entre as alternativas para equilibrar a estacionalidade da produção forrageira, o pastejo diferido tem se mostrado promissor, por ser de baixo custo e de fácil adoção. $\mathrm{O}$ pastejo diferido consiste em selecionar determinadas 
áreas de pasto e vedá-las ao acesso dos animais, no fim do verão. Dessa forma, é possível reservar o excesso de forragem produzida no período das águas, para pastejo direto durante o período de escassez. Vários autores (Euclides et al., 1990; Costa et al., 1993; Leite et al., 1998) demonstraram a viabilidade desta prática, desde que sejam selecionadas forrageiras adequadas para períodos de diferimento e de utilização específicos.

As plantas forrageiras mais indicadas para essa prática são aquelas que apresentam baixo acúmulo de colmos e boa retenção de folhas verdes, o que resulta em menores reduções no valor nutritivo ao longo do tempo. Para a região do Cerrado, Euclides et al. (1990) destacaram como promissora a Brachiaria decumbens, e Leite et al. (1998) a Brachiaria brizantha cultivar Marandu.

Vários autores mostraram que à medida que se aumenta o período de vedação, há acréscimos no acúmulo de forragem e decréscimos no seu valor nutritivo (Euclides et al., 1990; Costa et al., 1998; Leite et al., 1998). Assim, para conciliar maior produção com melhor qualidade, baseados em resultados de experimentos conduzidos em parcelas, Euclides \& Queiroz (2000) recomendaram a vedação e a utilização escalonadas das pastagens.

O objetivo deste trabalho foi avaliar o acúmulo de forragem, os componentes morfológicos e o valor nutritivo de pastos de Brachiaria decumbens cultivar Basilisk e de Brachiaria brizantha cultivar Marandu, diferidos em fevereiro e março e utilizados durante o período seco.

\section{Material e Métodos}

O experimento foi realizado na Embrapa Gado de Corte, Campo Grande, MS, de novembro de 1999 a outubro de 2003. O padrão climático da região, segundo Köppen, é o da faixa de transição entre Cfa e Aw tropical úmido. A precipitação média anual é de $1.560 \mathrm{~mm}$, e o período considerado de seca é de maio a setembro (30\% da precipitação anual). $\mathrm{O}$ balanço hídrico do período experimental encontra-se na Figura 1.

O solo da área experimental é classificado como Latossolo Vermelho distrófico. A análise química do solo (0-15 cm), antes da implantação dos pastos, mostrou os
A
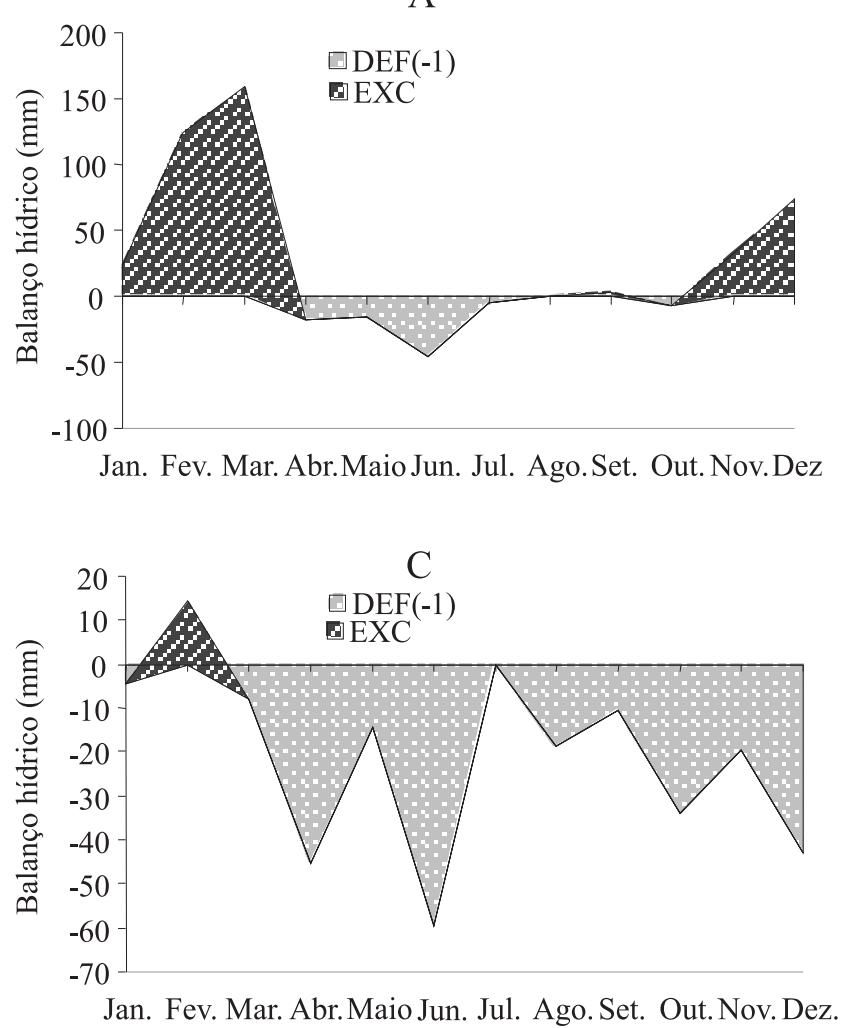

B

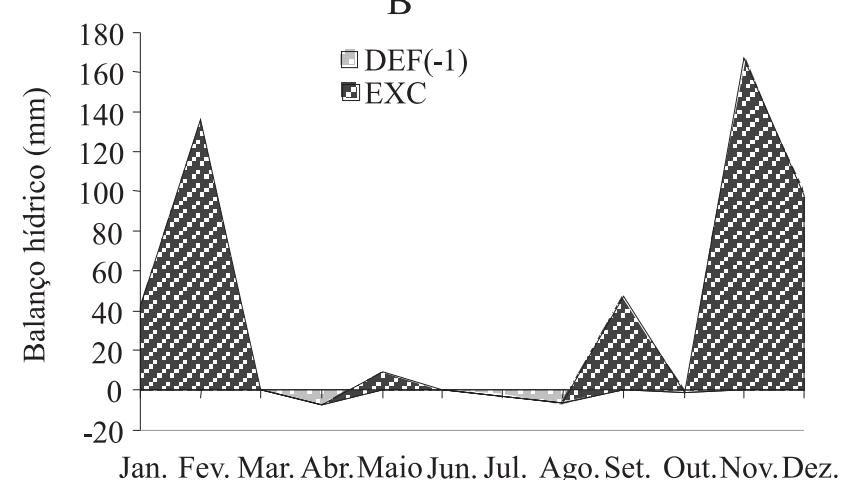

$\mathrm{D}$

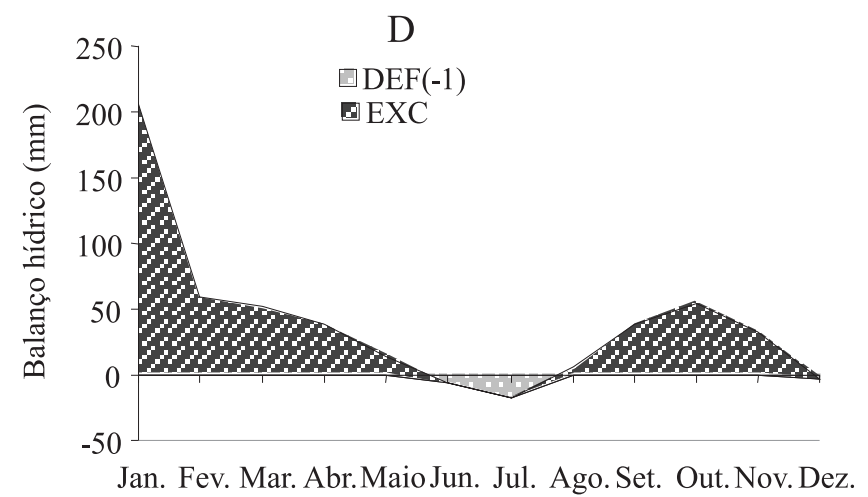

Figura 1. Extrato do balanço hídrico mensal, para os anos de 2000 (A), 2001 (B), 2002 (C) e 2003 (D). 
seguintes resultados: 5,36 de $\mathrm{pH}-\mathrm{H}_{2} \mathrm{O} ; 44,1 \mathrm{~g} \mathrm{~kg}^{-1}$ de matéria orgânica, $19 \%$ de saturação por bases; $39 \%$ de saturação

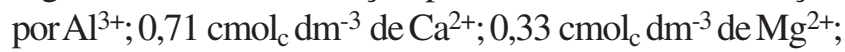
$0,11 \mathrm{~g} \mathrm{~kg}^{-1} \mathrm{de} \mathrm{K}^{+} ; 0,73 \mathrm{cmol}_{\mathrm{c}} \mathrm{dm}^{-3} \mathrm{de} \mathrm{Al}^{3+} ;$ e $1,68 \mathrm{mg} \mathrm{dm}^{-3}$ de P-Mehlich.

Foram utilizados 16,5 ha de Brachiaria decumbens cultivar Basilisk; e 16,5 ha de Brachiaria brizantha cultivar Marandu. As operações utilizadas na recuperação destes pastos foram: roçada, calagem e aração, em setembro de 1998, adubação e gradagem (grade niveladora), em dezembro de 1998. Foram aplicados $2 \mathrm{Mg} \mathrm{ha}^{-1}$ de calcário dolomítico (PRNT $=75 \%$ ), para elevar a saturação por base para 40\%, e $200 \mathrm{~kg} \mathrm{ha}^{-1} \mathrm{da}$ fórmula 5-20-20.

Em janeiro de 1999, foi realizada a semeadura com $2 \mathrm{e}$ 2,5 $\mathrm{kg} \mathrm{ha}^{-1}$ de sementes puras viáveis, respectivamente para $B$. decumbens e B. brizantha, cobertas, em seguida, com uma gradagem leve e compactadas com um rolo compactador de pneus.

Em outubro de 2001, foram aplicados, em cobertura, $320 \mathrm{~kg} \mathrm{ha}^{-1}$ de calcário filler $(\mathrm{PRNT}=91 \%)$, e em novembro, $200 \mathrm{~kg} \mathrm{ha}^{-1}$ da fórmula 0-20-20. Anualmente, na época do diferimento dos pastos, foram aplicados $110 \mathrm{~kg} \mathrm{ha}^{-1}$ de uréia em cobertura.

O delineamento experimental foi o de blocos ao acaso, com parcelas subdivididas, com quatro repetições. As parcelas principais foram constituídas pelas espécies de Brachiaria, e as subparcelas pela época de diferimento (fevereiro e março).

Os pastos foram utilizados, durante o período das águas, sob pastejo contínuo com taxa de lotação média de 1,5 UA ha ${ }^{-1}$. Cerca de uma semana antes da vedação, os pastos foram utilizados intensivamente, e os resíduos baixaram para $10 \mathrm{~cm}$ de altura. Oito piquetes de 1,5 ha (quatro de cada espécie) foram diferidos na primeira semana de fevereiro e utilizados a partir de meados de maio até meados de julho. Dez piquetes de 1,5 ha e seis de 1 ha (metade de cada espécie) foram diferidos na primeira semana de março e utilizados a partir de meados de julho até meados de outubro.

A utilização desses pastos, após a vedação, foi feita por novilhos com idade média de 21 meses e peso médio de $420 \mathrm{~kg}$. As taxas de lotação de cada piquete foram calculadas, tendo-se considerado o aproveitamento de $50 \%$ da quantidade de forragem acumulada durante o período de vedação, dividida pelo consumo diário do animal, estimado em $2 \%$ do peso vivo (PV) (Euclides et al., 2000), e multiplicado pelo número de dias em que os animais permaneceram no piquete.
Os pastos foram amostrados a cada 28 dias. A $5 \mathrm{~cm}$ do solo, 25 e 40 amostras de $0,25 \mathrm{~m}^{2}$ da forrageira foram cortadas, para os piquetes de 1 e 1,5 ha, respectivamente. Dessas amostras foram feitas duas subamostras, das quais uma foi secada e pesada, para se estimar a massa de matéria seca total; e a segunda foi separada em lâmina foliar, colmo (colmo e bainha) e material morto, e a proporção de cada fração foi expressa como porcentagem do peso total.

Para cada piquete, de cada cinco amostras por componente morfológico, foram feitas amostras compostas, que foram moídas a $1 \mathrm{~mm}$ e analisadas para se estimar o valor nutritivo, com uso da espectroscopia de reflectância do infra-vermelho próximo NIRS, Modelo NR5000, de acordo com Marten et al. (1985). Os dados de reflectância das amostras, na faixa de comprimentos de onda de 1.100 a $2.500 \mu \mathrm{m}$, foram armazenados em um espectrômetro acoplado a um microcomputador.

Como não foi utilizado animal fistulado no esôfago para amostrar esses pastos, procurou-se simular a dieta do animal, pela quantidade da massa de MST desaparecida correspondente à massa de MSV e à massa de MSLF. Assumiu-se que as relações do desaparecimento da forragem foram as mesmas da forragem ingerida pelo animal. Desta forma, a estimativa do valor nutritivo da dieta selecionada pelos animais foi calculada por meio de médias ponderadas, tendo-se considerado estas relações e os teores de PB, DVIMO, FDN e FDA, das frações de lâminas foliares e colmos.

Para ilustrar o potencial desses pastos para o desempenho animal, foi feita uma simulação com o modelo baseado no CNCPS (Fox et al., 2003), tendo-se usado machos cruzados castrados, com peso vivo médio inicial de aproximadamente $380 \mathrm{~kg}$ e peso de abate de $440 \mathrm{~kg}$, e consumo de matéria seca de forragem equivalente a $2 \%$ do PV (Euclides et al., 2000).

As análises estatísticas de todas as variáveis foram realizadas de acordo com o delineamento principal, segundo Steel \& Torrie (1980). O modelo matemático continha os efeitos fixos de gramíneas, época de diferimento, bloco, meses de utilização, ano de avaliação e as interações entre esses. As médias foram comparadas pelo teste de Tukey, adotando-se $5 \%$ de probabilidade.

As análises das massas de forragem, dos componentes morfológicos e das variáveis associadas ao valor nutritivo foram feitas pelo método dos quadrados mínimos, pelo procedimento "General Linear Model" do SAS Institute (1996). 


\section{Resultados e Discussão}

No ano da implantação dos pastos, em 1999, a média de produção de forragem, nos pastos em que a utilização se iniciou em maio, foi de 6,9 e 6,5 $\mathrm{Mg} \mathrm{ha}^{-1}$ de matéria seca total (MST) para B. decumbens e B. brizantha, respectivamente e, para aqueles em que a utilização se iniciou em julho, a média de produção foi de 4 e $3,8 \mathrm{Mg} \mathrm{ha}^{-1}$ de MST.

Não foram observadas interações entre os efeitos de espécies e época de diferimento, e entre os efeitos de espécies, época de diferimento e ano experimental, para a MST e para os componentes morfológicos dos pastos. No entanto, os pastos diferidos em fevereiro apresentaram maiores massas de MST, de matéria seca verde (MSV) e de matéria seca de lâminas foliares (MSLF). Houve, também, diferenças entre as épocas de vedação para os componentes morfológicos do pasto (Tabela 1).

A maior produção dos pastos diferidos em fevereiro, quando comparados aos diferidos em março, está de acordo com produções observadas para várias gramíneas, em várias regiões do Brasil: Mato Grosso do Sul (Euclides et al., 1990), Minas Gerais (Andrade \& Salgado, 1992; Andrade, 1993), Rondônia (Costa et al., 1993, 1998) e Distrito Federal (Leite et al., 1998).

Tabela 1. Médias e erros-padrão da média para as massas de matéria seca total (MST), de matéria seca verde (MSV) e de matéria seca de lâminas foliares (MSLF), das porcentagens de lâminas foliares, colmo e material morto dos pastos de $B$. brizantha cultivar Marandu e $B$. decumbens, diferidos em fevereiro e março ${ }^{(1)}$.

\begin{tabular}{lcc}
\hline Variável & Fevereiro & Março \\
\hline MST (kg ha ${ }^{-1}$ de MS) & $4.530 \pm 53 \mathrm{a}$ & $3.160 \pm 49 \mathrm{~b}$ \\
MSV (kg ha de MS) $^{-1}$ & $2.290 \pm 46 \mathrm{a}$ & $1.445 \pm 40 \mathrm{~b}$ \\
MSLF (kg ha de MS) & $935 \pm 20 \mathrm{a}$ & $680 \pm 18 \mathrm{~b}$ \\
Lâmina foliar (\%) & $18,4 \pm 0,5 \mathrm{~b}$ & $19,9 \pm 0,4 \mathrm{a}$ \\
Colmo (\%) & $27,2 \pm 0,6 \mathrm{a}$ & $22,2 \pm 0,5 \mathrm{~b}$ \\
Material morto (\%) & $54,4 \pm 0,8 \mathrm{~b}$ & $58,0 \pm 0,7 \mathrm{a}$ \\
\hline (1) Médias seguidas de letras iguais, na linha, não diferem entre si pelo \\
teste F, a 5\% de probabilidade.
\end{tabular}

Brachiaria brizantha apresentou maiores massas de MST, MSV e de MSLF do que a $B$. decumbens. Foram, também, observadas diferenças entre anos de avaliação, e para a interação entre os efeitos de gramínea e de ano (Tabela 2), para MST e MSLF.

Uma vez que a produção de forragem é dependente da temperatura e da radiação e é limitada pela disponibilidade de nutrientes e de água, a maior produção de forragem registrada em 2001 pode ser explicada pelo melhor balanço hídrico (Figura 1). A adubação de manutenção de P e K, feita no fim de 2001, não refletiu em maior produção de forragem em 2002 (Tabela 2), conseqüência possível do déficit hídrico observado neste ano, para todos os meses, exceto para janeiro e fevereiro. Para o resultado observado no ano de 2003, a explicação talvez esteja relacionada com o déficit hídrico registrado no ano anterior, que prejudicou a recuperação da planta forrageira após o período de utilização, o que se refletiu na baixa produtividade dos pastos em 2003, mesmo com o melhor balanço hídrico observado (Tabela 2).

Como as taxas de lotação foram ajustadas com base na massa de MST, elas apresentaram variações semelhantes às das disponibilidades de forragem nos anos experimentais (Tabela 2). As médias nos quatro anos foram de 3,26 e 3,09 novilhos por hectare, para os pastos de $B$. brizantha e $B$. decumbens, respectivamente.

Houve efeito da interação entre a época de diferimento e o período de utilização, mas não entre os efeitos de espécie, época de diferimento e período de utilização, para a MST, para os componentes morfológicos da planta e, consequientemente, para as MSV e MSLF. As variações dessas variáveis, ao longo do período de utilização dos pastos diferidos em fevereiro e março, independentemente da gramínea, são apresentadas na Tabela 3.

Tabela 2. Médias e erros-padrão da média para as massas de matéria seca total (MST; $\mathrm{kg} \mathrm{ha}^{-1} \mathrm{de}$ MS), de matéria seca verde (MSV; $\mathrm{kg} \mathrm{ha}^{-1}$ de MS), de matéria seca de lâminas foliares (MSLF; $\mathrm{kg} \mathrm{ha}^{-1}$ de MS) e as taxas de lotação (no de novilhos por hectare) dos pastos de $B$. brizantha cultivar Marandu e B. decumbens, diferidos em fevereiro e março ${ }^{(1)}$.

\begin{tabular}{|c|c|c|c|c|c|c|c|c|}
\hline \multirow[t]{2}{*}{ Ano } & \multicolumn{4}{|c|}{ Brachiaria brizantha } & \multicolumn{4}{|c|}{ Brachiaria decumbens } \\
\hline & MST & MSV & MSLF & TL & MST & MSV & MSLF & TL \\
\hline 2000 & $3.946 \pm 97 \mathrm{a}$ & $1.830 \pm 84$ & $720 \pm 38 b$ & $3,33 \pm 0,06 b$ & $3.270 \pm 105 \mathrm{c}$ & $1.520 \pm 91$ & $650 \pm 41 \mathrm{c}$ & $2,85 \pm 0,07 b$ \\
\hline 2001 & $4.535 \pm 106 a$ & $2.295 \pm 91$ & $900 \pm 41 \mathrm{a}$ & $3,68 \pm 0,11 \mathrm{a}$ & $4.570 \pm 117 \mathrm{a}$ & $2.350 \pm 101$ & $1.005 \pm 45 \mathrm{a}$ & $3,83 \pm 0,12 \mathrm{a}$ \\
\hline 2002 & $3.643 \pm 103 c$ & $1.815 \pm 89$ & $800 \pm 40 \mathrm{ab}$ & $2,89 \pm 0,09 \mathrm{c}$ & $3.765 \pm 108 b$ & $1.805 \pm 93$ & $730 \pm 42 b c$ & $3,16 \pm 0,10 b$ \\
\hline 2003 & $3.686 \pm 83 \mathrm{c}$ & $1.730 \pm 72$ & $890 \pm 33 a$ & $3,22 \pm 0,08 \mathrm{bc}$ & $3.375 \pm 87 \mathrm{c}$ & $1.570 \pm 75$ & $780 \pm 34 b$ & $2,94 \pm 0,07 b$ \\
\hline Média & $3.950 \pm 49$ & $1.920 \pm 41 \mathrm{~A}$ & $825 \pm 18$ & $3,26 \pm 0,05$ & $3.745 \pm 52$ & $1.815 \pm 44 \mathrm{~B}$ & $790 \pm 20$ & $3,09 \pm 0,06$ \\
\hline
\end{tabular}

${ }^{(1)}$ Médias seguidas de letras iguais, minúsculas na coluna e maiúsculas na linha, não diferem entre si pelo teste de Tukey, a $5 \%$ de probabilidade. 
Durante o período de utilização, independentemente da espécie forrageira e da época de diferimento, foram observados decréscimos nas massas de MST, MSV e MSLF, nas porcentagens de lâmina foliar (PF) e de colmo (Pco), e acréscimo na porcentagem de material morto (PM). Essa variação nos componentes morfológicos está relacionada não só à baixa taxa de rebrota e à senescência natural das gramíneas, acelerada pelo deficit hídrico durante esta época do ano (Figura 1), mas também ao processo de pastejo, uma vez que os animais selecionam folhas. Isto pode ser confirmado pelo desaparecimento de MST, que foi de $40 \%$ da massa de forragem disponível no início do período de utilização, comparado aos desaparecimentos de MSV e de MSLF, que foram de 75 e $80 \%$, respectivamente. Este padrão de variação está de acordo com os registrados por Euclides \& Medeiros (2003) para várias gramíneas tropicais, utilizadas durante o período seco.

Vale ressaltar que, apesar do decréscimo em massa de forragem durante todo o período seco, os pastos apresentaram valores superiores a 2,5 $\mathrm{Mg} \mathrm{ha}^{-1}$ de MST, o que indica que a disponibilidade de forragem total não foi um fator limitante à produção animal. As ofertas médias de forragem foram de 10,21 e 13,95 kg de MST por $100 \mathrm{~kg}$ de peso vivo (PV), 5,10 e 6,37 kg de MSV por $100 \mathrm{~kg}$ de PV, e 2,10 e 3,07 kg de MSLF por $100 \mathrm{~kg}$ de PV, para as épocas de diferimento. As maiores ofertas observadas para vedação em março foram consequiência do manejo adotado, pois a área diferida em fevereiro foi a metade daquela diferida em março, e o número de animais foi constante durante todo o período de utilização. Segundo Hodgson (1990), o consumo máximo ocorre quanto a oferta de forragem é de três a quatro vezes a necessidade diária do animal, assim a oferta de MST deveria ser de 10 a $12 \mathrm{~kg}$ por $100 \mathrm{~kg}$ de PV. No entanto, a independência entre a MST e o consumo de forragem foi observada por Euclides et al. (2000) para B. decumbens e B. brizantha, com correlações positivas entre MSV, MSLF e ingestão de forragem pelos animais. As ofertas de MSV e de MSLF limitaram, portanto, a ingestão máxima de forragem pelos animais.

Também foram observadas interações entre os efeito de espécies, de período de utilização e de ano experimental, para os componentes morfológicos do pasto, para as massas de MST, e conseqüentemente para as massas de MSV e MSLF (Tabela 4). Apesar dos padrões semelhantes entre as espécies para as épocas de diferimento (Tabela 3 ), as variações existentes entre anos são mais difíceis de ser ajustadas (Tabela 4) e denotam a influência das condições climáticas (Figura 1) sobre o comportamento de cada espécie, durante o período de utilização.

Não foram observadas interações entre os efeitos de espécies, época de diferimento e ano experimental; e entre espécies e ano experimental, para as variáveis avaliadas na estimativa do valor nutritivo dos pastos. Os teores de digestibilidade in vitro da matéria orgânica (DIVMO), fibra em detergente neutro (FDN) e lignina em detergente ácido (LDA), nas lâminas foliares, foram semelhantes para as duas espécies, com médias de 53,1, 70,4 e 3,4\%, respectivamente. No entanto, as lâminas foliares da $B$. decumbens apresentaram maiores conteúdos de proteína bruta (PB) do que às da $B$. brizantha, que foram, em média, 8,2 e 7,7\%, respectivamente. Não foram observadas diferenças nos teores de PB, DIVMO, FDN e LDA de ambas as espécies, com médias de 4,4, 41,8, 79,1 e $4,9 \%$, e $4,2,38,8,76,4$ e $4,8 \%$, respectivamente para os colmos e material morto. Esses valores foram semelhantes aos obtidos por Euclides et al. (2000) para essas duas espécies, utilizadas durante o período seco.

Inúmeros estudos demonstram que bovinos em pastejo selecionam dietas resultantes em composições químicas e botânicas diferentes daquelas encontradas na forragem disponível. Consomem folhas, em preferência

Tabela 3. Médias e os erros-padrão da média (EPM) para as massas de matéria seca total (MST, $\mathrm{kg} \mathrm{ha}^{-1}$ de MS), de matéria seca verde (MSV, $\mathrm{kg} \mathrm{ha}^{-1} \mathrm{de} \mathrm{MS),} \mathrm{de} \mathrm{matéria} \mathrm{seca} \mathrm{de} \mathrm{lâminas} \mathrm{foliares} \mathrm{(MSLF,} \mathrm{kg} \mathrm{ha}^{-1}$ de MS), para as porcentagens de lâmina foliares (LF) de colmo (Co) e de material morto (MM) dos pastos de B. brizantha cultivar Marandu e B. decumbens, diferidos em fevereiro e março, ao longo do período de utilização ${ }^{(1)}$.

\begin{tabular}{|c|c|c|c|c|c|c|c|}
\hline \multirow[t]{2}{*}{ Variável } & \multicolumn{3}{|c|}{ Fevereiro } & \multicolumn{3}{|c|}{ Março } & \multirow[t]{2}{*}{ EPM } \\
\hline & Maio & Junho & Julho & Julho & Agosto & Setembro & \\
\hline MST & $5.755 a$ & $4.615 b$ & $3.570 \mathrm{c}$ & $4.060 \mathrm{a}$ & $3.280 \mathrm{~b}$ & $2.500 \mathrm{c}$ & \pm 109 \\
\hline MSV & $3.780 \mathrm{a}$ & $1.775 b$ & $865 c$ & $2.385 \mathrm{a}$ & $1.050 \mathrm{~b}$ & $640 c$ & \pm 78 \\
\hline MSLF & $1.995 \mathrm{a}$ & $760 \mathrm{~b}$ & $360 \mathrm{c}$ & $1.285 \mathrm{a}$ & $425 b$ & $300 c$ & \pm 42 \\
\hline LF & $30,2 a$ & $16,8 b$ & $10,3 c$ & $31,4 a$ & $13,4 b$ & $12,6 b$ & $\pm 1,2$ \\
\hline $\mathrm{Co}$ & $36,4 \mathrm{a}$ & $22,5 b$ & $14,2 \mathrm{c}$ & $27,1 \mathrm{a}$ & $19,3 b$ & $13,9 \mathrm{c}$ & $\pm 1,3$ \\
\hline MM & $33,4 \mathrm{c}$ & $60,8 \mathrm{~b}$ & $75,5 \mathrm{a}$ & $41,4 \mathrm{c}$ & $67,3 \mathrm{~b}$ & $73,6 \mathrm{a}$ & $\pm 1,7$ \\
\hline
\end{tabular}


aos colmos, e forragem verde em preferência à morta. Conseqüentemente, quando comparada com a forragem disponível, a dieta selecionada pelos animais apresenta maior valor nutritivo. Euclides et al. (2000) observaram que, durante o período seco, a PF dos pastos de B. decumbens e B. Brizantha cultivar Marandu foram, respectivamente, de 19,2 e 21,2\%; no entanto, a PF nas extrusas foram de 89,7 e 84,2 \%, respectivamente.

A relação MST:MSV foi de 1:1, para ambos os períodos de diferimento, e de 1:0,40 e 1:0,55, para a relação MST:MSLF, para os pastos diferidos em fevereiro e março, respectivamente.A dieta selecionada foi constituída de $100 \%$ da fração verde da planta, e, desta, 40 e $55 \%$ das dietas foram constituídas de lâmina foliar, para os pastos diferidos em fevereiro e março, respectivamente.

Não foram observadas diferenças entre as espécies forrageiras e entre períodos de vedação, para as variáveis associadas ao valor nutritivo dos componentes morfológicos. Entretanto, as amostras que simularam o pastejo animal, nos pastos diferidos em março, apresentaram maiores teores de PB e DIVMO e menores conteúdos de FDN e LDA, em relação aos diferidos em fevereiro. As médias foram: 6,7 e 6,2\% de PB; 48,4 e 47,2\% de DIVMO; 74,0 e 75,1\% de FDN; e 4,1 e $4,2 \%$ de FDA, respectivamente. Como os pastos

Tabela 4. Médias anuais e erro-padrão da média (EPM) para as massas de matéria seca total, de matéria seca verde e de matéria seca de lâminas foliares dos pastos de B. brizantha cultivar Marandu e B. decumbens, diferidos em fevereiro e março, ao longo do período de utilização ${ }^{(1)}$.

\begin{tabular}{|c|c|c|c|c|c|c|}
\hline \multirow[t]{2}{*}{ Ano } & \multicolumn{3}{|c|}{ B. decumbens } & \multicolumn{3}{|c|}{ B. brizantha } \\
\hline & Maio & Junho & Julho & Julho & Agosto & Setembro \\
\hline & \multicolumn{6}{|c|}{ Matéria seca total $\left(\mathrm{kg} \mathrm{ha}^{-1}\right)$} \\
\hline 2000 & $4.440 \mathrm{~b}$ & $3.570 \mathrm{~b}$ & $3.290 \mathrm{~b}$ & $5.340 \mathrm{~b}$ & $4.040 \mathrm{~b}$ & $2.700 \mathrm{~b}$ \\
\hline 2001 & $6.340 \mathrm{a}$ & $5.050 \mathrm{a}$ & $3.720 \mathrm{a}$ & $6.150 \mathrm{a}$ & $5.225 \mathrm{a}$ & $4.275 \mathrm{a}$ \\
\hline 2002 & $3.865 \mathrm{c}$ & $3.220 \mathrm{~b}$ & $2.550 \mathrm{c}$ & $4.830 \mathrm{bc}$ & $3.630 \mathrm{~b}$ & $2.415 \mathrm{c}$ \\
\hline 2003 & $4.100 \mathrm{bc}$ & $3.290 \mathrm{~b}$ & $2.450 \mathrm{c}$ & $4.040 \mathrm{c}$ & $3.550 \mathrm{~b}$ & $2.875 b$ \\
\hline \multirow[t]{2}{*}{ EPM } & \pm 280 & \pm 222 & \pm 188 & \pm 219 & \pm 195 & \pm 183 \\
\hline & \multicolumn{6}{|c|}{ Matéria seca verde $\left(\mathrm{kg} \mathrm{ha}^{-1}\right)$} \\
\hline 2000 & $2.870 \mathrm{a}$ & $1.350 \mathrm{a}$ & $690 \mathrm{a}$ & $2.820 \mathrm{~b}$ & $1.340 \mathrm{a}$ & $412 b$ \\
\hline 2001 & $4.505 \mathrm{a}$ & $1.960 \mathrm{a}$ & $790 \mathrm{a}$ & $3.670 \mathrm{a}$ & $1.290 \mathrm{a}$ & $980 \mathrm{a}$ \\
\hline 2002 & $2.280 \mathrm{~b}$ & $1.420 \mathrm{~b}$ & $830 \mathrm{a}$ & $3.165 \mathrm{~b}$ & $1.180 \mathrm{a}$ & $635 \mathrm{ab}$ \\
\hline 2003 & $2.525 b$ & $1.390 \mathrm{~b}$ & $810 \mathrm{a}$ & $2.830 \mathrm{~b}$ & $1.370 \mathrm{a}$ & $885 a$ \\
\hline \multirow[t]{2}{*}{ EPM } & \pm 154 & \pm 150 & \pm 159 & \pm 155 & \pm 146 & \pm 164 \\
\hline & \multicolumn{6}{|c|}{ Matéria seca de lâminas foliares $\left(\mathrm{kg} \mathrm{ha}^{-1}\right)$} \\
\hline 2000 & $1.265 \mathrm{bc}$ & $515 a$ & $265 \mathrm{a}$ & $1.350 \mathrm{c}$ & $645 a$ & $190 b$ \\
\hline 2001 & $2.050 \mathrm{a}$ & $660 \mathrm{a}$ & $300 \mathrm{a}$ & $1.795 \mathrm{a}$ & $635 \mathrm{a}$ & $455 \mathrm{a}$ \\
\hline 2002 & $1.060 \mathrm{c}$ & $535 a$ & $385 \mathrm{a}$ & $1.565 b$ & $590 \mathrm{a}$ & $300 \mathrm{ab}$ \\
\hline 2003 & $1.415 b$ & $485 \mathrm{a}$ & $320 \mathrm{a}$ & $1.410 \mathrm{c}$ & $680 \mathrm{a}$ & $440 \mathrm{a}$ \\
\hline EPM & \pm 85 & \pm 71 & \pm 59 & \pm 81 & \pm 75 & \pm 68 \\
\hline
\end{tabular}

${ }^{(1)}$ Médias seguidas de letras iguais, na linha, dentro de espécie, não diferem entre si pelo teste de Tukey, a 5\% de probabilidade. permaneceram vedados de três e cinco meses, é normal que os valores nutritivos destes sejam inferiores aos mesmos pastos sob pastejo, como observado por Euclides et al. (2000).

Os valores nutritivos dos componentes morfológicos e da dieta que simulou o pastejo animal variaram com o ano experimental. As médias das duas espécies por ano experimental estão descritas na Tabela 5.

Não foram observadas interações dos efeitos de espécies e de período de utilização, entre época de diferimento e período de utilização, entre ano experimental e período de utilização, entre espécies, época de diferimento e período de utilização, e entre espécie, ano experimental e período de utilização. Mas, houve decréscimos nos teores de PB e de DIVMO, e acréscimos nos conteúdos de FDN e LDA das lâminas foliares e da dieta que simulou o pastejo animal durante o período de utilização (Tabela 6). No entanto, a variação no valor nutritivo do colmo e do material morto foi pequena durante o período de utilização (Tabela 6).

Decréscimos nos teores de PB e de DIVMO, durante o período de utilização, foram também observados para

Tabela 5. Médias e os erros-padrão da média para os teores de proteína bruta $(\mathrm{PB})$, de digestibilidade in vitro da matéria orgânica (DIVMO), da fibra em detergente neutro (FDN) e de lignina em detergente ácido (LDA), das lâminas foliares, dos colmos, do material morto e da simulação da dieta dos animais em pastos de B. brizantha cultivar Marandu e B. decumbens, diferidos em fevereiro e março, de acordo com o ano de $\operatorname{avaliação}^{(1)}$.

\begin{tabular}{lrrrr}
\hline Variável & 2000 & 2001 & 2002 & \multicolumn{1}{c}{2003} \\
\hline PB (\%) & $8,5 \pm 0,12 \mathrm{a}$ & $8,1 \pm 0,14 \mathrm{a}$ & $7,6 \pm 0,13 \mathrm{~b}$ & $7,7 \pm 0,10 \mathrm{~b}$ \\
DIVMO (\%) & $54,6 \pm 0,43 \mathrm{a}$ & $53,0 \pm 0,47 \mathrm{a}$ & $53,4 \pm 0,45 \mathrm{a}$ & $51,9 \pm 0,36 \mathrm{~b}$ \\
FDN (\%) & $70,5 \pm 0,27 \mathrm{a}$ & $70,0 \pm 0,30 \mathrm{ab}$ & $69,7 \pm 0,28 \mathrm{~b}$ & $71,0 \pm 0,23 \mathrm{a}$ \\
LDA (\%) & $3,3 \pm 0,05 \mathrm{~b}$ & $3,2 \pm 0,05 \mathrm{~b}$ & $3,2 \pm 0,05 \mathrm{~b}$ & $3,6 \pm 0,04 \mathrm{a}$ \\
\hline \multicolumn{5}{c}{ Colmo } \\
PB (\%) & $5,6 \pm 0,55 \mathrm{a}$ & $5,0 \pm 0,42 \mathrm{a}$ & $4,9 \pm 0,40 \mathrm{a}$ & $4,0 \pm 0,31 \mathrm{~b}$ \\
DIVMO (\%) & $42,4 \pm 0,33 \mathrm{a}$ & $43,3 \pm 0,61 \mathrm{a}$ & $3,1 \pm 0,58 \mathrm{a}$ & $39,8 \pm 0,46 \mathrm{~b}$ \\
FDN (\%) & $78,7 \pm 0,32 \mathrm{~b}$ & $78,2 \pm 0,36 \mathrm{~b}$ & $78,3 \pm 0,34 \mathrm{~b}$ & $80,4 \pm 0,27 \mathrm{a}$ \\
LDA (\%) & $5,0 \pm 0,06 \mathrm{~b}$ & $4,5 \pm 0,07 \mathrm{c}$ & $4,7 \pm 0,07 \mathrm{~b}$ & $5,4 \pm 0,05 \mathrm{a}$ \\
\hline \multicolumn{5}{c}{ Material morto } \\
PB (\%) & $4,8 \pm 0,37 \mathrm{a}$ & $4,3 \pm 0,41 \mathrm{a}$ & $4,1 \pm 0,38 \mathrm{a}$ & $3,8 \pm 0,31 \mathrm{a}$ \\
DIVMO (\%) & $39,0 \pm 0,49 \mathrm{a}$ & $40,1 \pm 0,54 \mathrm{a}$ & $39,2 \pm 0,51 \mathrm{a}$ & $37,5 \pm 0,41 \mathrm{~b}$ \\
FDN (\%) & $76,5 \pm 0,35 \mathrm{~b}$ & $74,8 \pm 0,39 \mathrm{c}$ & $75,7 \pm 0,37 \mathrm{bc}$ & $77,5 \pm 0,29 \mathrm{a}$ \\
LDA (\%) & $5,0 \pm 0,06 \mathrm{a}$ & $4,2 \pm 0,06 \mathrm{c}$ & $4,7 \pm 0,06 \mathrm{~b}$ & $5,0 \pm 0,05 \mathrm{a}$ \\
\hline \multicolumn{5}{c}{ Simulação da dieta } \\
PB (\%) & $7,1 \pm 0,17 \mathrm{a}$ & $6,6 \pm 0,18 \mathrm{ab}$ & $6,2 \pm 0,18 \mathrm{bc}$ & $6,0 \pm 0,14 \mathrm{c}$ \\
DIVMO (\%) & $48,9 \pm 0,41 \mathrm{a}$ & $48,4 \pm 0,45 \mathrm{a}$ & $48,5 \pm 0,42 \mathrm{a}$ & $46,1 \pm 0,34 \mathrm{~b}$ \\
FDN (\%) & $74,4 \pm 0,24 \mathrm{~b}$ & $73,9 \pm 0,26 \mathrm{~b}$ & $73,8 \pm 0,25 \mathrm{~b}$ & $75,5 \pm 0,20 \mathrm{a}$ \\
LDA (\%) & $4,1 \pm 0,05 \mathrm{~b}$ & $3,8 \pm 0,05 \mathrm{c}$ & $4,1 \pm 0,05 \mathrm{~b}$ & $4,4 \pm 0,04 \mathrm{a}$ \\
\hline
\end{tabular}

(1)Médias seguidas de letras iguais, na linha, não diferem entre si pelo teste de Tukey, a $5 \%$ de probabilidade. 
pastos de B. decumbens (Euclides et al., 1990) e B. brizantha (Costa et al., 1993), diferidos em fevereiro e março. Esses autores encontraram teores de PB e de DIVMO, durante todo o período de utilização, superiores aos encontrados neste trabalho. Essa diferença pode ser explicada pela natureza dos trabalhos, pois os resultados encontrados na literatura são oriundos de experimentos em regime de corte, e o presente foi realizado sob pastejo. Em condições de pastejo, a média de valor nutritivo da forragem disponível é inferior àquela observada em sistema de corte, uma vez que, sob pastejo, o animal rejeita parte da forragem, que continua decrescendo em qualidade. Neste caso, o pasto disponível é uma combinação da rebrota, que é muito baixa nessa época do ano, e da forragem recusada.

O baixo desempenho animal em pastos de gramíneas do gênero Brachiaria durante o período seco, pode ser explicado pela deficiência protéica (Euclides \& Medeiros, 2003). O nível crítico de PB na dieta, abaixo do qual o consumo é reduzido pela deficiência de $\mathrm{N}$, foi

Tabela 6. Médias e os erros-padrão da média para os teores de proteína bruta (PB), de digestibilidade in vitro da matéria orgânica (DIVMO), da fibra em detergente neutro (FDN) e de lignina em detergente ácido (LDA), das lâminas foliares, dos colmos, do material morto e da simulação da dieta dos animais em pastos de $B$. brizantha cultivar Marandu e B. decumbens, diferidos em fevereiro e março, durante o período de utilização ${ }^{(1)}$.

\begin{tabular}{lrcr}
\hline Variável & \multicolumn{3}{c}{ Período de utilização (dias) } \\
\cline { 2 - 4 } & \multicolumn{3}{c}{ Lâminas foliares } \\
\hline & $9,23 \pm 0,11 \mathrm{a}$ & $7,72 \pm 0,11 \mathrm{~b}$ & $6,98 \pm 0,10 \mathrm{c}$ \\
PB (\%) & $55,68 \pm 0,37 \mathrm{a}$ & $52,63 \pm 0,37 \mathrm{~b}$ & $51,35 \pm 0,37 \mathrm{c}$ \\
DIVMO (\%) & $69,74 \pm 0,23 \mathrm{a}$ & $70,24 \pm 0,23 \mathrm{a}$ & $70,96 \pm 0,23 \mathrm{~b}$ \\
FDN (\%) & $3,28 \pm 0,04 \mathrm{a}$ & $3,37 \pm 0,04 \mathrm{a}$ & $3,48 \pm 0,04 \mathrm{~b}$ \\
LDA (\%) & \multicolumn{4}{c}{ Colmo } \\
\hline \multicolumn{4}{c}{$5,25 \pm 0,32 \mathrm{a}$} \\
PB (\%) & $4,98 \pm 0,33 \mathrm{a}$ & $4,33 \pm 0,32 \mathrm{a}$ \\
DIVMO (\%) & $42,26 \pm 0,48 \mathrm{a}$ & $42,30 \pm 0,47 \mathrm{a}$ & $41,86 \pm 0,47 \mathrm{a}$ \\
FDN (\%) & $79,10 \pm 0,28 \mathrm{a}$ & $78,62 \pm 0,28 \mathrm{a}$ & $79,02 \pm 0,28 \mathrm{a}$ \\
LDA (\%) & $4,91 \pm 0,05 \mathrm{a}$ & $4,82 \pm 0,05 \mathrm{a}$ & $4,88 \pm 0,05 \mathrm{a}$ \\
\hline \multicolumn{4}{c}{ Material morto } \\
PB (\%) & $4,22 \pm 0,31 \mathrm{a}$ & $4,69 \pm 0,31 \mathrm{a}$ & $3,84 \pm 0,31 \mathrm{~b}$ \\
DIVMO (\%) & $38,26 \pm 0,42 \mathrm{a}$ & $39,04 \pm 0,42 \mathrm{a}$ & $39,53 \pm 0,42 \mathrm{a}$ \\
FDN (\%) & $76,85 \pm 0,30 \mathrm{a}$ & $75,45 \pm 0,30 \mathrm{~b}$ & $76,05 \pm 0,30 \mathrm{~b}$ \\
LDA (\%) & $4,84 \pm 0,05 \mathrm{a}$ & $4,64 \pm 0,05 \mathrm{~b}$ & $4,68 \pm 0,05 \mathrm{~b}$ \\
\hline & & Simulação dieta \\
PB (\%) & $7,22 \pm 0,15 \mathrm{a}$ & $6,52 \pm 0,151 \mathrm{~b}$ & $5,69 \pm 0,15 \mathrm{c}$ \\
DIVMO (\%) & $49,50 \pm 0,35 \mathrm{a}$ & $47,72 \pm 0,35 \mathrm{~b}$ & $46,73 \pm 0,35 \mathrm{~b}$ \\
FDN (\%) & $74,11 \pm 0,21 \mathrm{a}$ & $74,31 \pm 0,21 \mathrm{ab}$ & $74,84 \pm 0,21 \mathrm{~b}$ \\
LDA (\%) & $4,05 \pm 0,04 \mathrm{a}$ & $4,64 \pm 0,04 \mathrm{a}$ & $4,68 \pm 0,04 \mathrm{a}$ \\
\hline (1)Médias seguidas de mesma letra, na linha, não diferem entre si pelo & \\
teste de Tukey, a $5 \%$ de probabilidade.
\end{tabular}

estimado entre 6 e 7\% para as gramíneas tropicais (Minson, 1990). Considerando-se a dieta que simulou o pastejo do animal, o conteúdo de PB esteve abaixo do valor crítico, exceto no início da utilização dos pastos. Este fato é um indício de que o conteúdo de PB foi fator limitante à produção animal

Tanto para o componente lâmina foliar quanto para a forragem disponível (Tabela 6), houve decréscimos nos teores de DIVMO ao longo do período de utilização, o que pode ser explicado pela observação feita por Euclides (2000) de que as maiores mudanças que ocorrem na composição química das gramíneas tropicais são aquelas que acompanham a maturação. À medida que a planta amadurece, a concentração dos componentes potencialmente digestíveis, compreendendo os carboidratos solúveis, proteína, minerais e outros conteúdos celulares, tende a decrescer. Ao mesmo tempo, as proporções de lignina, celulose e hemicelulose, e outras frações indigestíveis, tais como cutícula e sílica, aumentam. Logo, o decréscimo na digestibilidade é esperado.

O resultado da simulação baseado no CNCPS (Fox et al., 2003) mostrou que a deficiência de energia para mantença é de 1,16 Mcal por dia. Para ganho de peso dos animais nesses pastos, portanto, além da suplementação protéica, faz-se necessária também a suplementação energética.

\section{Conclusões}

\section{Brachiaria decumbens e Brachiaria brizantha} são adequadas para o diferimento no final do verão, com vistas à utilização durante o período crítico.

2. O diferimento dos pastos, para ambas as espécies, possibilita grande incremento na taxa de lotação durante todo o período seco.

3. Independentemente da época de diferimento, os conteúdos de proteína bruta e de energia dos pastos de Brachiaria decumbens e de Brachiaria brizantha são fatores limitantes à produção animal.

\section{Referências}

ANDRADE, I.F. Efeito da época de vedação na produção e valor nutritivo do capim-elefante (Pennisetum purpureum Shum.) cv. Mineiro. Revista da Sociedade Brasileira de Zootecnia, v.22, p.53-63, 1993.

ANDRADE, I.F.; SALGADO, J.G.F. Efeito da época de vedação do capim-elefante (Pennisetum purpureum Shum.) cultivar Cameroon sobre a produção e valor nutritivo. Revista da Sociedade Brasileira de Zootecnia, v.21, p.637-646, 1992. 
COSTA, N.L.; OLIVEIRA, J.R. da C.; PAULINO, V.T. Efeito do diferimento sobre o rendimento de forragem e composição química de Brachiaria brizantha cv. Marandu em Rondônia. Revista da Sociedade Brasileira de Zootecnia, v.22, p.495-505, 1993.

COSTA, N.L.; OLIVEIRA, J.R. da C.; TOWNSEND, C.R. Efeito do diferimento sobre a produção e composição química do capimelefante cv. Mott. Pesquisa Agropecuária Brasileira, v.33, p.497500,1998 .

EUCLIDES, V.P.B. Alternativas para intensificação da produção de carne bovina em pastagem. Campo Grande: Embrapa Gado de Corte, 2000. 65p.

EUCLIDES, V.P.B. Produção intensiva de carne bovina em pasto. In: SIMPÓSIO DE PRODUÇÃO DE GADO DE CORTE, 2., 2001, Viçosa. Anais. Viçosa: UFV, 2001. p.55-82.

EUCLIDES, V.P.B.; CARDOSO, E.G.; MACEDO, M.C.M.; OLIVEIRA, M.P. Consumo voluntário de Brachiaria decumbens cv. Basilisk e Brachiaria brizantha cv. Marandu sob pastejo. Revista da Sociedade Brasileira de Zootecnia, v.29, p.2200-2208, 2000.

EUCLIDES, V.P.B.; MEDEIROS, S.R. de. Valor nutritivo das principais gramíneas cultivadas no Brasil. Campo Grande: Embrapa Gado de Corte, 2003. 43p. (Embrapa Gado de Corte. Documentos, 139).

EUCLIDES, V.P.B.; VALLE, C.B. do; SILVA, J.M. da; VIEIRA, A. Avaliação de forrageiras tropicais manejadas para a produção de fenoem-pé. Pesquisa Agropecuária Brasileira, v.25, p.393-407, 1990.

EUCLIDES FILHO, K.; QUEIROZ, H.P. de. Manejo de pastagens para produção de feno-em-pé. Campo Grande: Embrapa Gado de Corte, 2000. 4p. (Embrapa Gado de Corte. Gado de Corte Divulga, 39).
FOX, D.G.; TYLUTKI, T.P.; TEDESCHI, L.O.; VAN AMBURGH, M.E.; CHASE, L.E.; PELL, A.N.; OVERTON, T.R.; RUSSEL, J.B. Sistema de carboidratos e proteínas 'líquidos' para a avaliação da nutrição de rebanhos e excreção de nutrientes (CNCPS Versão 5.0): documentação do modelo CNCPS. Juiz de Fora: Embrapa Gado de Leite, 2003. 202p. Tradução Fernando César Ferraz Lopes, Heloísa Carneiro, Jaílton da Costa Carneiro, Limirio de Almeida Carvalho, Oriel Fajardo de Campos, Pedro Braga Arcuri.

HODGSON, J. Grazing management: science into practice. Hong Kong: Longman Scientific \& Technical, 1990. 203p.

LEITE, G.G.; COSTA, N.L.; GOMES, A.C. Épocas de diferimento e utilização de gramíneas cultivadas na região do Cerrado. Planaltina: Embrapa-CPAC, 1998. 23p. (Embrapa-CPAC. Boletim de pesquisa, 40).

MARTEN, G.C.; SHENK, J.S.; BARTON II, F.E. Near infrared reflectance spectroscopy (NIRS): analysis quality. Washington: USDA, 1985. 110p. (Agriculture handbook, 643).

MINSON, D.J. Forage in ruminant nutrition. San Diego: Academic Press, 1990. 483p.

PIZARRO, E.A.; VALLE, C.B.; SÉLLER-GREIN, G.; SCHULTZEKRAFT, R.; ZIMMER, A.H. Regional experience with brachiaria: Tropical America-savannas. In: MILES, J.W.; MAASS, B.L.; VALLE, C.B. (Ed.). Brachiaria: biology, agronomy and improvement. Calli: CIAT; Campo Grande: Embrapa-CNPGC, 1996. p.225-246.

SAS INSTITUTE (Cary, Estados Unidos). SAS/STAT user software: changes and enhancements through release. Version 6.11. Cary, 1996. 2v.

STEEL, R.G.D.; TORRIE, J.H. Principles and procedures of statistics. New York: McGraw-Hill, 1980. 663p. 